\title{
A PROPOSAL FOR THE CLASSIFICATION OF TOXIC SUBSTANCES WITHIN THE FRAMEWORK OF LIFE CYCLE ASSESSMENT OF PRODUCTS
}

\author{
Jeroen Guineé" \& Reinout Heijungs \\ Centre of Environmental Science, Leiden University \\ P.O. Box 9518,2300 RA Leiden, The Netherlands
}

(Received in Germany 30 November 1992; accepted 5 February 1993)

\begin{abstract}
Quantitative life cycle assessment (LCA) is a method allocating the environmental impacts of the whole life cycle of a product to the functioning of that product. The scientific basis of the method is still being elaborated. In this paper a proposal is made to improve the scientific basis of one specific step of the method: the aggregation of potentially toxic emissions of substances in one score for human toxicity and two scores for ecotoxicity. The aggregation is based on multimedia environmental models of Mackay simulating the behaviour of substances in the environment, and on toxicity data such as acceptable resp. tolerable daily intake (ADI resp. TDI) and no observed effect concentration (NOEC) per substance. It is proposed to apply models describing the environmental fate of toxic substances in LCAS of products. In addition, it is proposed to adopt the concept of a reference substance, as used in the ozone depletion potential (ODP) and the global warming potential (GWP), to assess and aggregate emissions of potentially toxic substances.
\end{abstract}

\section{INTRODUCTION}

The principle of life cycle assessment, abbreviated LCA, as a tool for product oriented environmental management, has become widely accepted, both in Europe [1] and in the USA [2]. An LCA is an analyzing tool for the assessment of the environmental impact of the functioning of a product. That the functioning of a product does not only include the usage of the product, but also the production, transportation, maintenance and waste handling, is reflected in the term life cycle. Among possible applications are the comparison of product alternatives and the (re)design of products in an environmentally optimal way.

Life cycle assessment is a rapidly developing area of applied environmental science. One of the recent activities in the field of LCA is the development of a methodological framework. Within this framework five components may be distinguished: goal definition, inventory, classification, valuation and improvement analysis $[3,4,5]$.

In the goal definition, the subject of study is determined. This includes a description of the amount of function investigated, the so-called functional unit. An example of a functional unit is "packaging of one sandwich". Using this functional unit, packaging systems of different materials (polyethene, aluminium, paper, etc.) can be compared.

The next component of an LCA is the inventory. Within the inventory, the life cycle of each of the products considered is defined by assembling data of the processes which constitute the life cycle. Examples of processes considered are 
production of materials and components, transport, use and maintenance of products, and waste handling and recycling. Process data consist of economical data (use and production of materials, products and services) and of environmental data (extractions of resources and emissions of substances). The result of the inventory is a list of inputs from and outputs to the environment in terms of extractions and emissions caused by a functional unit of the product studied.

In the classification, scientific knowledge of environmental processes is used to estimate the contribution of all extractions and emissions to a limited number of generally recognized environmental problems. For emissions of substances, this is achieved by multiplying emissions by a classification factor, which is defined per type of problem and per mass unit of a substance emitted. The aim of the classification factor is to provide a scientific basis for the comparison of products on potential environmental effects. It is not an indicator of the actual effects. Classification and valuation are sometimes treated as a unitarv_enmnnnent under the_heading imnactanalusis If] 
etc. $[18,19]$. Other methods aim to provide a quantitative integrated assessment of toxic substances. For this, models are developed relating emissions to exposure concentrations $[20,21,22,23]$, and assessing the potential effects of these exposures $[24,25]$. Within the framework of LCA it is practically impossible to aim for a site-specific assessment of emissions of toxic substances, taking into account site-specific conditions like the number of people living in the neighbourhood of a factory, the distance between factory and residential districts, the presence of specific ecosystems, the soil composition of that particular site, etc. For such a site-specific assessments other instruments have been developed, e.g. environmental impact assessment (EIA). In LCA a product is the starting point of the assessment, which includes an inventory of the emissions of a large number of processes all over the world. It seems practically impossible to gather site specific data for all these processes. In an EIA, the assessment is limited to one or two activities at a specific site allowing a site-specific elaboration of the assessment. In LCA it is thus necessary to abstract from aspects which differ per site and to include these aspects, if possible at all, in a generic way (e.g. in percentages per area).

In this paper a method is proposed to improve the "critical volumes approach" applying the quantitative integrated model approach and deriving formulae for classification factors. The paper is an elaboration of recent work [26]. We propose to distinguish between human toxicity and ecotoxicity and define, similar to the ODP- and GWP-concepts, a so-called HTP (human toxicity potential), a TETP (terrestrial ecotoxicity potential) and an AETP (aquatic ecotoxicity potential) for each substance. With these classification factors an emission of a substance to a compartment $m_{\text {subs,comp }}$ can be expressed in terms of an emission of a reference substance $m_{l}$ :

$$
m_{l}=L_{\text {subs,comp }} \times m_{\text {subs,comp }}
$$

where $L_{\text {subs,comp }}$ is the classification factor of substance subs initially emitted to compartment comp.

The general calculation procedure for each of these potentials is the same. Each potential in principle exists of two parts: an exposure part translating a particular emission to a dose to which a receptor is exposed (human or ecosystem), and an effect part translating a particular exposure dose to possible effects on potential receptors. The exposure and the effect part have to be defined for each exposure route and for each substance and the reference substance for the HTP, as well as for the TETP and the AETP. Combination of the exposure and the effect part relative to the exposure and the effect part for the reference substance yields the classification factor, which represents the potential contribution of a unit amount of a given substance to human toxicity, terrestrial ecotoxicity resp. aquatic ecotoxicity relative to a unit amount of a reference substance emitted to a reference compartment.

The general principle of the classification factors, the exposure parts, the effect parts, the combination of these parts into the different classification factors and the necessary further developments will be discussed subsequently.

\section{GENERAL PRINCIPLE}

The exposure part of the classification factor should preferably be based on multi-media environmental models such as developed by Mackay [23]. Until today, these models are mainly applied for the assessment of substances, for example in the Netherlands [24, 25]. In the widely used level III models of Mackay, a diffuse emission flux into a predefined standard environment ("unit world") is assumed, leading to a steady-state partitioning between environmental compartments based on processes such as (ad)sorption, deposition, evaporation and leaching, and taking into account degradation processes. In this way equilibrium concentrations are calculated due to emission fluxes. Notice that this implies that high exposure concentrations, possibly occurring before the equilibrium concentration is reached and resulting in acute toxic effects, cannot be considered with these models. Toxicity assessments based on Mackay level III models are thus limited to chronic toxic effects. Mackay models are linear models in the sense that partitioning coefficients and lifetimes of a particular substance 
are independent from the concentration of that substance.

Mackay models cannot be applied directly to emissions as quantified in LCAS, because LCA-emissions are not restricted to a certain period of time. Emissions of a substance during the product's entire life cycle take place at a non-homogeneous and unknown rate. An LCA is only concerned with the total emission of a substance associated with the entire life cycle of a product, which is regarded as a pulse (in $\mathbf{k g}$ ). Multi-media environmental models, which take into account time-dependent processes such as degradation and partitioning, are necessarily based on a flux (in $\mathrm{kg} \times \mathrm{day}^{-1}$ ). There is a relation between the flux and the equilibrium concentration. Increasing the flux leads to an increased concentration, and thus to an increased risk.

In principle, two types of solutions for the flux-pulse problem are possible:

- to assume an arbitrary time-period during which the emission takes place;

- to select a reference substance and calculate a dimensionless classification factor per substances similar to the ODP-, GWP- and POCP-concepts.

The first type of solution is not very elegant and can lead to arbitrary results dependent on the time-period chosen. The second solution seems elegant and quite simple to elaborate at the same time and is worked out here. Below, the concept of the reference substance is developed in detail.

When the relation between the flux $\Phi_{\text {subs }}$ of a substance subs and the toxic effect $T_{\text {subs }}$ is assumed to be linear, we have

$$
T_{\text {subs }}=\frac{K_{\text {subs }}}{N E L_{\text {subs }}} \times \Phi_{\text {subs }}
$$

where $K_{\text {subs }}$ is an exposure modelling constant, which depends on properties of substance subs such as lifetime and partitioning coefficients and the exposure routes, and $N E L_{\text {ssbs }}$ is a no-effect level for substance subs, which is regarded as a measure for its toxicity to a specified receptor.

The flux is defined as the mass $m_{\text {subs }}$ emitted during some unit time $t$ :

$$
\Phi_{s u b s}=\frac{m_{s u b s}}{t}
$$

In an LCA the mass emitted is known, but the time period during which the emission takes place is unspecified. To be able to use the modelling equation (2), we will avoid the unknown time $t$ by adopting the concept of a reference substance. For a reference substance refsubs one has, similar to (2) and (3)

$$
T_{\text {ressubs }}=\frac{K_{\text {refsubs }}}{N E L_{\text {refsubs }}} \times \Phi_{\text {refsubs }}=\frac{K_{\text {refsubs }}}{N E L_{\text {refsubs }}} \times \frac{m_{\text {refsubs }}}{t}
$$

One can combine (2), (3) and (4) in order to eliminate the unknown $t$ :

$$
m_{\text {refsubs }}=\Phi_{\text {refsubs }} \times \frac{1}{\Phi_{\text {subs }}} \times m_{\text {subs }}=\frac{T_{\text {refunbs }} \times N E L_{\text {refsubs }}}{K_{\text {refsubs }}} \times \frac{K_{\text {subs }}}{T_{s u b s} \times N E L_{\text {subs }}} \times m_{\text {subs }}
$$

From this, it is possible to calculate the mass of the reference substance, required to cause a toxic effect equal to the toxic effect of substance subs caused by the specified emission of $m_{\text {subs }}$. This mass of the reference substance will be denoted by $m_{l}$ : 


$$
m_{t}=m_{\text {regabs }} \text { such that } T_{\text {resubs }}=T_{\text {smbr }}
$$

and is given by

$$
m_{l}=\frac{K_{\text {smbe }} / N E L_{\text {subs }}}{K_{\text {refsubs }} / N E L_{\text {refubs }}} \times m_{\text {seds }}
$$
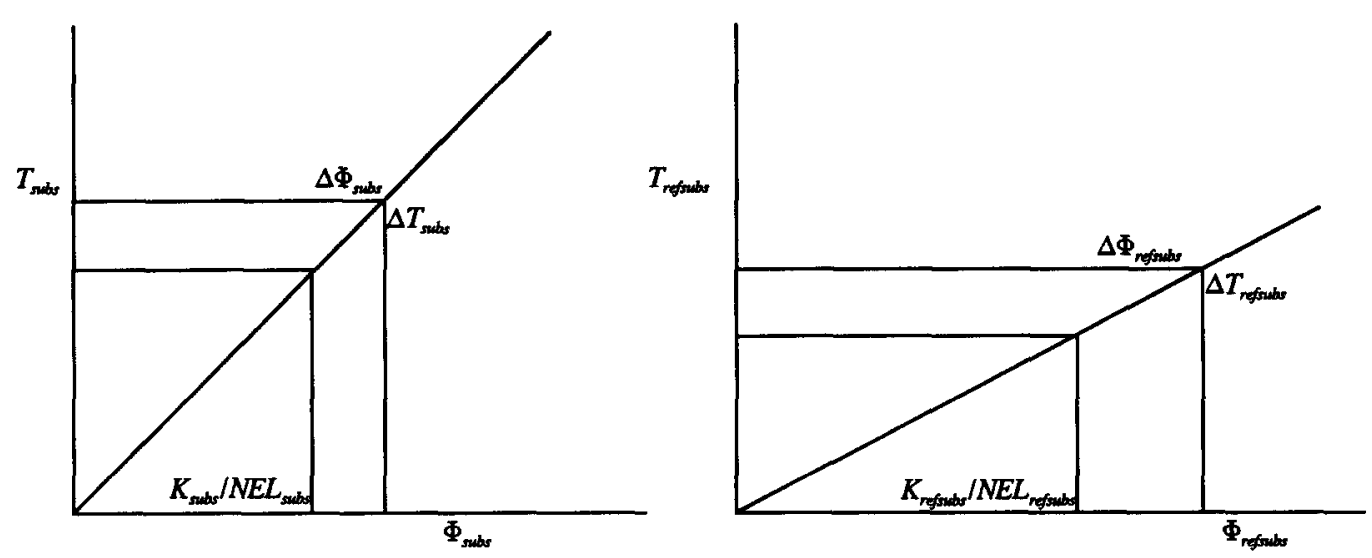

Figure 1: $\Delta \Phi_{\text {rgsobss }}$ is defined such that $\Delta T_{\text {refsubs }}=\Delta T_{\text {subs }}$.

This is illustrated in figure 1 . To account for the fact that the eventual exposure concentrations depend on the initial compartment the substance is emitted to, equation (7) can be extended with a subscript comp denoting this initial emission compartment. The reference substance is thus also specified in terms of a reference emission compartment refcomp:

$$
m_{l}=\frac{K_{\text {subs,comp }} / N E L_{\text {subs }}}{K_{\text {refsubs, rofeomp }} / N E L_{\text {refubs }}} \times m_{\text {subs,comp }}
$$

A final complication arises by the fact that the no-effect levels may differ per intake route. For human toxicity a distinction will thus be made between a respiratory NEL and an oral NEL. This set-up also enables the future inclusion of more routes, e.g. dermal intake. The total toxic effect is found as the sum of the partial toxic effects over all routes:

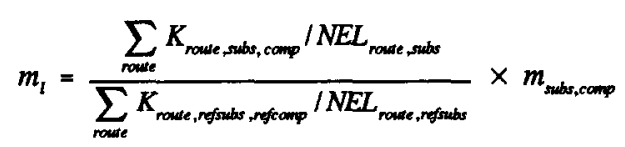

Now, $m_{t}$ denotes the mass of the reference substance emitted to the reference compartment, required to cause a toxic effect equal to the toxic effect of substance subs caused by the specified emission $m_{\text {subs,comp }}$ to compartment comp. It will be clear that the classification factor is dimensionless, and that the classification factor of the reference substance is equal to one. 


\section{THE EXPOSURE PART}

Below, the exposure part of the classification factor will be elaborated for human and ecosystems exposure. The latter will be subdivided per compartment: exposure of terrestrial ecosystems and of aquatic ecosystems.

\section{The human exposure part}

Exposure of human beings to toxic substances can take place by the consumption of food and beverages (drinking water, fish, crops, meat, and dairy products), by respiration and by uptake through the skin. In figure 2 these exposure routes are schematically drawn [cf. 24,25 ].

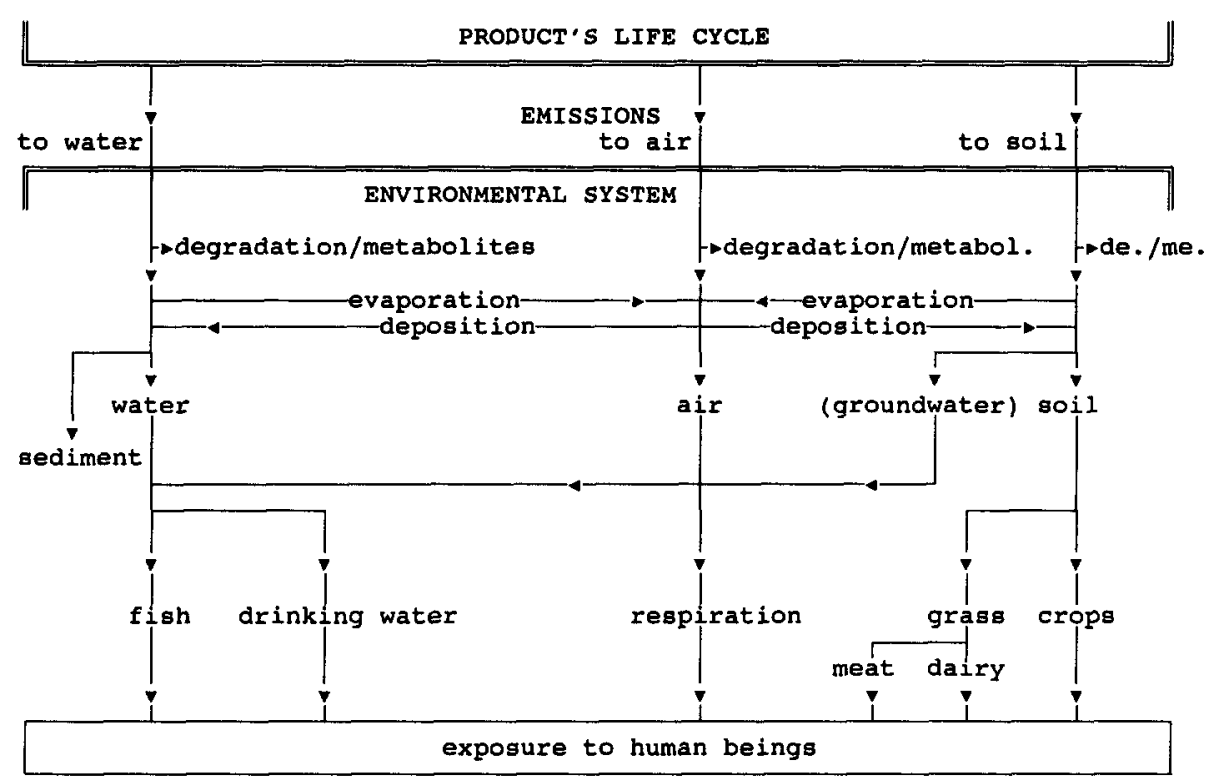

Figure 2: Routes of human exposure to toxic substances. Groundwater and uptake through skin contact not yet included in standard Mackay model.

The total daily exposure to a substance subs emitted to compartment comp is denoted by $I_{\text {subs,comp }}$ and is related to the flux $\Phi_{\text {subs, comp }}$ by the modelling constant $K_{\text {subs,comp: }}$ :

$$
K_{\text {subs,comp }}=\frac{I_{\text {subs,comp }}}{\Phi_{\text {subs, comp }}}
$$

Because human exposure through respiration will have to be assessed with another no-effect level than human exposure through oral intake, this modelling constant $K_{\text {subs,comp }}$ is subdivided into two parts: the respiratory modelling constant $K_{r, s u b s, c o m p}$ and the oral modelling constant $K_{o, \text { subs,comp. }} \boldsymbol{K}_{r, \text { subs,comp }}$ is defined as:

$$
K_{r, \text { subs }, \text { comp }}=\frac{I_{r, \text { subs,comp }}}{\Phi_{\text {subs, comp }}}
$$

where $I_{r, \text { subs,comp }}$ is the daily human exposure by respiration, defined as 


$$
I_{r, \text { subs }, \text { camp }}=C_{r, \text { subs,comp }} \times \dot{V}_{r} \quad C_{r, \text { subs,comp }}=C_{\text {air subs,comp }} \text { (see discussion) }
$$

where $C_{r, s u b, c o m p}$ is the concentration of substance subs initially emitted to compartment comp in the air respired (route), $C_{\text {ari,subs,comp }}$ is the concentration of substance subs initially emitted to compartment comp in the compartment air of the "unit world" and $\dot{V}$, is the average volume of air respirated by a human being per day.

The oral modelling constant $K_{o, \text { subs,comp }}$ is composed of five parts (see figure 2): the daily exposure by consumption of drinking water, consumption of fish, consumption of crops, consumption of meat, and consumption of dairy products [24]. For each of these routes a specific modelling constant can be defined. In formula:

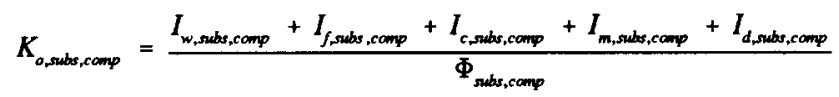

These partial intakes will be worked out subsequently, largely based on Toet et al. [24] and De Nijs \& Vermeire [27] (see formula box).

$$
\begin{aligned}
& I_{w, \text { subs,comp }}=C_{w, \text { subs,comp }} \times \dot{V}_{w} \quad C_{w, \text { subs,comp }}=C_{\text {water,subs,comp }} \text { (see discussion) }
\end{aligned}
$$

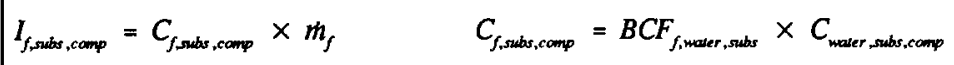

$$
\begin{aligned}
& I_{c, \text { subs }, \text { comp }}=C_{c, \text { subs, comp }} \times m_{c} \quad C_{r, \text { shbs,comp }}=B C F_{c, \text { sailliq, subs }} \times C_{\text {soilitiq subs, comp }}
\end{aligned}
$$

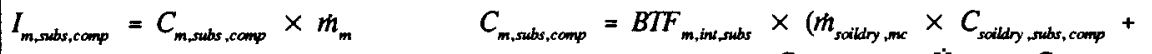

$$
\begin{aligned}
& \left.+m_{d g, m c} \times C_{d g \text { subs,camp }}+\dot{V}_{r, m c} \times C_{\text {air subs, comp }}\right) \\
& C_{d g, \text { shbs, comp }}=b_{\text {dur, unt }} \times C_{\text {wg,subs,comp }}=
\end{aligned}
$$

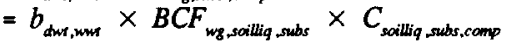

$$
\begin{aligned}
& I_{d, \text { subs, comp }}=C_{d, \text { subs,comp }} \times m_{d} \\
& C_{d, \text { shbs,comp }}=B T F_{d, \text { int, subs }} \times\left(m_{\text {soiltry, de }} \times C_{\text {saildy , subs, comp }}+\right. \\
& \left.+m_{d g, d c} \times C_{d g, s, s b s, c o m p}+\dot{V}_{r, d c} \times C_{a i r, \text { subs,comp }}\right)
\end{aligned}
$$

where:

- $C_{w, \text { subs,comp }}$ is the concentration in drinking water of substance subs emitted to compartment comp and other symbols represent a similar quantity for resp. fish, wet crops, meat, dry grass, wet grass and dairy products;

- $\quad C_{\text {water,subs,comp }}$ is the concentration in (unpurified) surface water of substance subs emitted to compartment comp, other symbols represent a similar quantity for resp. the liquid fraction in soil, the solid fraction of the soil (= dryweight) and dryweight grass;

- $\quad B C F_{f, \text { weter,sub }}$ is the bioconcentration factor $[28,29,30,31]$ linking a concentration of a substance in water to a concentration in fish, other symbols represent a similar quantity for wet crops (or grass)-liquid soil fraction $\left(B C F_{\text {wg,soiliq,subs }}=B C F_{c, \text { soillig, subs }}\right)$;

- $\quad B T F_{m, i n s, n b s}$ is the biotransfer factor which links the animals' daily intake of a substance subs to the concentration in wetweight meat, another symbol represent a similar quantity for dairy products-daily intake;

- other symbols are explained in table 4 . 


$$
K_{\text {airssubs,comp }}=\frac{C_{\text {air,subs,comp }}}{\Phi_{\text {subs,comp }}}
$$

equation (11) can now be rewritten as

$$
K_{r, \text { subs,comp }}=K_{\text {air,subs, comp }} \times \dot{V}
$$

and, equation (13) as

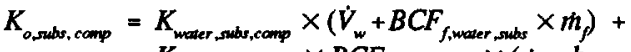

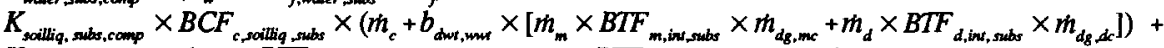

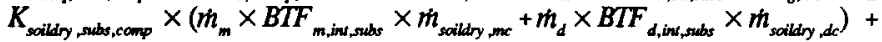

$$
\begin{aligned}
& K_{\text {dir,subs,comp }} \times\left(m_{m} \times B T F_{m, \text { in }, \text { subs }} \times \dot{V}_{r, m c}+m_{d} \times B T F_{d, \text { in , subs }} \times \dot{V}_{r, d c}\right)
\end{aligned}
$$

$K_{\text {air,subs,comp }}, K_{\text {water,subs,comp }}, K_{\text {soilliq,subs,comp }}$ and $K_{\text {saidry,subs,comp }}$ are modelling constants relating a flux of a substance subs, emitted to compartment comp, to a concentration in air resp. water or soil (concentration in soilwater resp. concentration in total dryweight soil). They are derived from the multimedia level III model of Mackay [23]. By estimating the daily intake $\dot{V}$ or $\dot{m}$ of air, drinking water, fish, crops, meat and dairy products by humans [27], the daily intake of dry soil and of dry grass by cattle, the conversion factor $b$ and estimating BCFs and BTFs by the octanol/water coefficients $K_{\text {ow }}[28,29,30,31]$, the $K_{r, \text { subs,comp }}$ and the $K_{o, \text { subs,comp }}$ can be calculated. This calculation procedure can also be followed for the reference substance.

\section{The ecosystem exposure part}

In the classification of ecotoxic substances, effects will be subdivided per compartment for the time being. As specific toxicity data for ecosystems in the sediment [32] and for exposure of ecosystems by air are lacking, these compartments are not yet considered. The classification of ecotoxic substances is thus limited to the compartments land soil (terrestrial ecosystems) and surface water (aquatic ecosystems). Thus, two exposure parts can be distinguished: one for exposure of terrestrial ecosystems and one for exposure of aquatic ecosystems. Again, the multimedia environmental model of Mackay [23] is used to calculate the exposure modelling constants for both terrestrial and aquatic exposure. However, the exposure routes towards man are not considered of course. In this case, the modelling constants $K_{\text {soildy,subs,camp }}$ and $K_{\text {water,subs,comp }}$ derived from Mackay models are applied directly for terrestrial resp. aquatic ecosystems.

\section{THE EFFECT PART}

As mentioned before, exposure of human beings or ecosystem species can result in a large number of effects. Apart from this, while human toxicity concerns the potential toxic effects of one species (human beings), ecotoxicity concerns the potential toxic effects of a large number of species. The question how to deal with these aspects in a no-effect level then arises.

Two possible methods can be distinguished. The first is to relate environmental exposure concentrations to the types of mechanisms initiated in humans and in ecosystem species, such as carcinogenity, mutagenity, decrease of reproduction capacity, etc. The second method is to relate the exposure concentrations to the first occurring adverse effect (based on the parameter measured in a specific toxicity test, e.g. growth, mortality, immune response, etc.) and to base the no-effect level 
on the threshold value for that effect.

The first method is not feasible because knowledge on mechanisms is far from complete, and because it would result in a great number of effect scores, which would be difficult to handle in practice. The second method is current practice in modelling $[24,33]$. For these reasons, it is proposed here to base the no-effect levels on a threshold value for the first occurring adverse effect.

\section{The human effect part}

For human toxicity, two no-effect levels are distinguished: for oral effects and for respiratory effects. Since the exposure takes place by intake, the NEL should be formulated as a no-effect intake (NEI). As NEI-values for the oral no- effect level for human toxicity, the so-called acceptable daily intake (ADI) values and the so-called tolerable daily intake (TDI) values can be applied. ADIs are determined by the Wbrld Health Organization (WHO) for a limited number of substances. TDIS have been derived by the Dutch National Institute for Public Health and Environmental Protection (RIVM) for a number of priority substances for the soil sanitation [34]. For some of these priority substances an ADI was already defined by the wHO. Then the TDI is equal to the ADI. If an ADI is lacking for a priority substance, a TDI-value has been derived from comprehensive toxicological literature research.

ADIS and TDIs, can only be defined for effects that occur at doses above a certain threshold value. Carcinogenity and genotoxicity are effects for which such threshold values cannot be defined. Any dose is considered hazardous. However, by defining tolerable risk levels, e.g. an increased risk on cancer of $10^{-4}$ [34], so-called virtually safe concentrations (vscs) have been derived. These vsCs are the basis for TDIs for carcinogenic or genotoxic substances [34].

As NEI-values for respiratory intake the so-called tolerable air concentration (TAC) developed by the RIVM [34] can be applied. Daily exposure to contaminated air up to the TAC-value is assumed to be equal in effect on human health to a daily oral dose the size of the TDI-value. The air quality guidelines (AQG) of the wHO [35] can be applied as $N E I_{r, \text { subs }}$ for substances for which no TAC has been defined yet. In both cases, a conversion is required: since the modelling constants for the respiratory and the oral route have the same dimension, the NEI-values should be made comparable too. The TAC and the

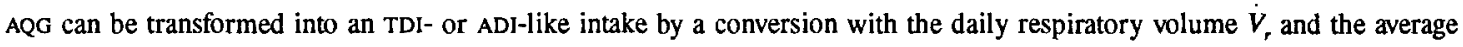
body weight $M$ :

$$
N E I_{r, s \text { ubs }}=\frac{\dot{V}_{r}}{M} \times(T A C \text { or } A Q G)
$$

If for a substance both the TAC and the AQG are lacking, the TDI or ADI can be used directly. In that case, it is thus assumed that the effect of a substance is independent from the exposure route (respiratory or oral). The hierarchy of toxicity data that can be applied as $N E I_{o, \text { subs }}$ and $N E I_{r, s u b s}$, is summarized in table 1 . The minimal toxicity entry needed is the TDI or the ADI.

\section{The ecosystem effect part}

For terrestrial and aquatic ecotoxicity, the no-effect level of a toxic substance is defined as the no (adverse) effect concentration (NEC) of the substance considered for terrestrial resp. aquatic ecosystems.

The derivation of the $N E C_{t, \text { subs }}$ and the $N E C_{a, s \text { subs }}$ poses the problem that a NEC has to be derived for all relevant species of the ecosystem considered. The current way of determining the $N E C_{t, \text { subs }}$ and the $N E C_{a, \text { subs }}$ is to extrapolate them from single species toxicity data, such as the lethal concentration for $50 \%$ of the organisms $\left(\mathrm{LC}_{\mathrm{so}}\right)$, the effect concentration for $50 \%$ of the organisms $\left(\mathrm{EC}_{\mathrm{S}_{0}}\right)$ and the no observed effect concentration (NOEC). To this end, several extrapolation methods have been proposed [36]. The us Envimonmental Protection Agency (EPA) proposed a set of - quite arbitrary - extrapolation factors 
Table 1: Hierachy of toxicity data that can be applied as NEI for the human effect part.

\begin{tabular}{|c|c|c|}
\hline hierarchy & toxicity data for $N E I_{o, s u b s}$ & toxicity data for $N E I_{r, \text { subs }}$ \\
\hline 1 & TDI or ADI & $\dot{V} / M \times \mathrm{TAC}$ \\
\hline 2 & - & $\dot{V} / M \times \mathrm{AQG}$ \\
\hline 3 & - & TDI or ADI \\
\hline
\end{tabular}

for deriving ecosystem values from single species toxicity data, taking into account the lack of data and the variance among species and assuming that $95 \%$ of all species of the ecosystem will be protected by this value [37]. The Dutch RIVM proposed some modifications for the original EPA-concept [38]. This modified EPA-method, just like the original EPAmethod, estimates an "environmental concern level", which can be applied as $N E C_{t, \text { ssbs }}$ and $N E C_{a, \text { subs. }}$. The method assumes that the ratios between acute and chronic toxicity and between laboratory single species toxicity data and field ecosystem effects are constant. The extrapolation factors used depend on the availability of single species data of members of particular taxonomic groups.

Table 2: Extrapolation factors to derive "environmental concern levels", which can be applied as a $N E C_{t, s u b s}$.

available information

lowest acute $\mathrm{LC}_{50}, \mathrm{EC}_{50}$ or QSAR estimate of acute toxicity

lowest acute $\mathrm{LC}_{50}, \mathrm{EC}_{50}$ or QSAR-estimate of acute toxicity for at least one representative of microbe-mediated processes, one representative of earthworms or arthropods and one representative of plants

lowest chronic NOEC or QSAR-estimate of chronic toxicity for at least one representative of microbe-mediated processes, one representative of earthworms or arthropods and one representative of plants extrapolation factor

0.001

$0.01^{*}$

$0.1^{*}$

- Lowest value is selected in case $\mathrm{LC}_{S 0} \mathrm{~S}$, $\mathrm{EC}_{\mathrm{SO}}$, NOECS or QSARS are not available for a representative of all three taxonomic groups.

The extrapolation factors related to the available information to derive "environmental concern levels", which can be used as $N E C_{t, s u b s}$, are given in table 2. The extrapolation factors used to derive "environmental concern levels", which can be used as $N E C_{a, s w b s}$, are given in table 3 [38].

Van Straalen and Denneman [39] proposed a method defining so-called $\mathrm{HC}_{p}$-values (hazardous concentration for $p \%$ of the species) for ecosystems based on a method developed by Kooijman [40]. Some modifications of the method were proposed by Aldenberg and Slob [41]. The basis for the calculation of such a $\mathrm{HC}_{p}$-value for a substance and an ecosystem are a number of (at least four) NOEC-values for characteristic and/or sensitive species. The $\mathrm{HC}_{p}$-value for ecosystems is then calculated, based on these single species values, in a statistical way assuming a log-logistic distribution of NOEC-values for 
Table 3: Extrapolation factors to derive "environmental concern levels", which can be applied as a $N E C_{a, \text { shbs }}$.

\begin{tabular}{ll}
\hline available information & extrapolation factor \\
\hline lowest acute $\mathrm{LC}_{50}, \mathrm{EC}_{50}$ or QSAR estimate of acute toxicity & 0.001 \\
$\begin{array}{l}\text { lowest acute } \mathrm{LC}_{50}, \mathrm{EC}_{50} \text { or QSAR-estimate of acute toxicity for at least one representative of algae, } \\
\text { one representative of crustaceans and one representative of fish }\end{array}$ & $0.01^{*}$ \\
$\begin{array}{l}\text { lowest chronic NOEC or QSAR-estimate of chronic toxicity for at least one representative of algae, } \\
\text { one representative of crustaceans and one representative of fish }\end{array}$ & $0.1^{*}$ \\
\hline
\end{tabular}

- Lowest value is selected in case $\mathrm{LC}_{50}, \mathrm{EC}_{50}$, NOECS or QSARS are not available for a representative of all three taxonomic groups.

* MicroTox data may be used.

different species and protecting 95\% $(p=5)$ of the species. Wagner and Løkke developed a similar approach based on a lognormal distribution of NOEC-values for different species [42].

These more sophisticated extrapolation methods cannot be applied on a large scale for the time being, because for quite a number of substances toxicity data are not sufficiently available. At this moment, the EPA-approach can be applied to any substance of which at least one $\mathrm{LC}_{50}, \mathrm{EC}_{50}$, NOEC or a QSAR-estimation of one of these toxicity data is known. For reasons of comparibility, it would not be appropriate to mix the EPA-approach with the more sophisticated extrapolation methods. Hence, it is proposed to apply the practical, though quite arbitrary, EPA extrapolation method for the time being.

\section{THE CLASSIFICATION FACTOR}

Combination of the exposure part and the effect part yields the classification factor. The classification factor for human toxicity is called the human toxicity potential (HTP). For an emission of substance subs to compartment comp it is defined as

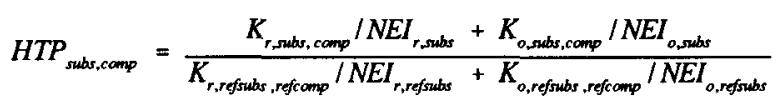

For the exposure parts (the different $K s$ ) equation (20) and (21) are elaborated according to the model description given above for both the substance studied and the reference substance. For the effect parts (the different NEIs) table 1 is used. The potential human toxic effect of the emission of a substance subs to compartment comp can now be expressed as an emission $m_{h}$ of a reference substance to a reference compartment with an equivalent effect:

$$
m_{h}=H T P_{\text {subs,comp }} \times m_{\text {subs,comp }}
$$

The classification factor for terrestrial ecotoxicity is called the terrestrial ecotoxicity potential (TETP) and is defined as

$$
T E T P_{\text {subs, comp }}=\frac{K_{\text {solitery subs, comp }} / N E C_{t, \text { subs }}}{K_{\text {soildy, refsubs, refecomp }} / N E C_{t, \text { refssubs }}}
$$


where table 2 is used for the no-effect concentration. The potential terrestrial ecotoxic effect of the emission of a substance subs to compartment comp can now be expressed as an emission $m_{1}$ of a reference substance to a reference compartment with an equivalent effect:

$$
m_{t}=T E T P_{\text {subs,comp }} \times m_{\text {subs, comp }}
$$

The aquatic ecotoxicity potential (AETP) is defined in a similar way:

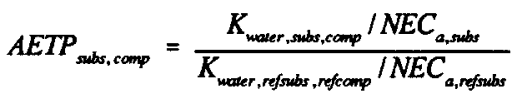

Here table 3 is used for the determination of the NECs. The potential aquatic ecotoxic effect of the emission of a substance subs to compartment comp can now be expressed as an emission $m_{a}$ of a reference substance to a reference compartment with an equivalent effect:

$$
m_{a}=A E T P_{\text {subs,comp }} \times m_{\text {subs,comp }}
$$

The HTP, TETP and AETP have the following properties:

- they are dimensionless;

- they are equal to one for the reference substance emitted to the reference compartment;

- they are higher for a more toxic substance and (almost) zero for a harmless substance;

- they are higher for a more persistent substance, and almost zero for a highly degradable substance.

\section{EXAMPLE}

The method described above is a theory which may be used to assess the potential toxic effects of emissions of chemicals. It is not a model to predict empirical phenomena which can be validated, such as concentrations. The particular part of the method based on the multimedia environmental models has been validated by Mackay et al. [43, 44] as far as possible. Predicted and observed environmental concentrations appeared to be in a reasonable range.

To show what the results of the theoretical model as proposed above might look like and to show that the theoretical model is feasible in practice, we calculated the HTPS, TETPS and AETPS of phenol (chosen as the reference substance) and benzene. Air was chosen as reference compartment. We emphasize that the primary aim of this example is to illustrate a new method for the assessment of emissions of toxic chemicals within the framework of LCA and not to give the ultimate HTP, TETP- and AETP-values for these substances. We selected these two substances for practical reasons, as data for these substances are quite well available and they fit into the fugacity approach without any further adaptations (see discussion).

The level III model and data applied to calculate the environmental concentrations are largely based on a model described by Mackay \& Paterson [44]. Additional data needed to calculate the HTPS, TETPS and AETPS of phenol and benzene are shown in table 4. The values are reported by Toet et al. [24] and De Nijs \& Vermeire [27]. A comprehensive listing of the model applied here is available from the authors on request.

The physical properties and toxicity data of phenol and benzene needed as input for a HTP, TETP and AETP calculation with a Mackay Level III model are shown in table 5 along with their values. The values are from Mackay [23], Mackay \& Paterson [44], Howard [45], Vermeire et al. [34], Stortelder $e t$ al. [46] and Denneman \& van Gestel [47]. 
Table 4: Input data for the calculation of HTPS, TETPS and AETPS $[24,27]$.

\begin{tabular}{|c|c|c|c|}
\hline symbol & quantity & value & unit \\
\hline$M$ & human mass & 70.0 & $\mathrm{~kg}$ \\
\hline$b_{\text {dur, num }}$ & factor for conversion of wet plant weight to dry plant weight & 4.0 & - \\
\hline$\dot{m}_{d, d c}$ & dairy cattle daily dryweight grass consumption & 16.9 & $\mathrm{~kg} \times \mathrm{day}^{-1}$ \\
\hline$\dot{m}_{\text {soildry,de }}$ & dairy cattle daily dryweight soil consumption & 0.41 & $\mathrm{~kg} \times$ day $^{-1}$ \\
\hline$\dot{V}_{r, d c}$ & dairy cattle daily respiratory volume & 122 & $\mathrm{~m}^{3} \times \mathrm{day}^{-1}$ \\
\hline$\dot{m}_{d g, m c}$ & meat cattle daily dryweight grass consumption & 12.2 & $\mathrm{~kg} \times$ day $^{-1}$ \\
\hline$\dot{m}_{\text {soildry,me }}$ & meat cattle daily dryweight soil consumption & 0.39 & $\mathrm{~kg} \times \mathrm{day}^{-1}$ \\
\hline$\dot{\boldsymbol{V}}_{r, m c}$ & meat cattle daily respiratory volume & 122 & $\mathrm{~m}^{3} \times$ day $^{-1}$ \\
\hline$\dot{m}_{f}$ & human daily fish consumption & 0.01 & $\mathrm{~kg} \times \mathrm{day}^{-1}$ \\
\hline$\dot{m}_{\mathrm{c}}$ & human daily wetweight crops consumption & 0.558 & $\mathrm{~kg} \times$ day $^{-1}$ \\
\hline$\dot{m}_{m}$ & human daily meat consumption & 0.126 & $\mathrm{~kg} \times$ day $^{-1}$ \\
\hline$\dot{m}_{d}$ & human daily dairy products consumption & 0.371 & $\mathrm{~kg} \times$ day $^{-1}$ \\
\hline$\dot{V}_{w}$ & human daily drinking water volume & 2.0 & $1 \times$ day $^{-1}$ \\
\hline$\dot{V}_{r}$ & human daily respiratory volume & 20.0 & $\mathrm{~m}^{3} \times \mathrm{day}^{-1}$ \\
\hline
\end{tabular}

The results of the calculations are shown in tables 6 and 7 . 
Table 5: The physical properties and toxicity data of phenol and benzene.

\begin{tabular}{|c|c|c|c|}
\hline quantity & unit & phenol & benzene \\
\hline molecular weight & $\mathrm{g} \times \mathrm{mol}^{-1}$ & $94.1[23]$ & $78.1[23]$ \\
\hline vapor pressure at $25^{\circ} \mathrm{C}$ & $\mathrm{Pa}$ & $70.6[23]$ & $1.27 \times 10^{4}[23]$ \\
\hline water solubility & $\mathrm{g} \times \mathrm{m}^{-3}$ & $8.20 \times 10^{4}[23]$ & $1.78 \times 10^{3}[23]$ \\
\hline${ }^{10}$ og octanol-water coefficient & - & $1.46[23]$ & $2.13[23]$ \\
\hline melting point & ${ }^{\circ} \mathrm{C}$ & 40.9 [23] & $5.53[23]$ \\
\hline degradation rate constant air & $h^{-1}$ & $4.62 \times 10^{-2}[45]$ & $8.60 \times 10^{-4}[44]$ \\
\hline degradation rate constant water & $h^{-1}$ & $2.17 \times 10^{-2}[45]$ & $4.80 \times 10^{-3}[44]$ \\
\hline degradation rate constant soil & $h^{-1}$ & $2.27 \times 10^{-1}[45]$ & 0 \\
\hline degradation rate constant sediment & $h^{-1}$ & 0 & 0 \\
\hline$N E C_{\text {r.subs }}$ & $\mathrm{kg} \times \mathrm{m}^{-3}$ & $2.10 \times 10^{-7}[34]$ & $3.00 \times 10^{-8}[34]$ \\
\hline$N E I_{o, s u b s}$ & $\mathrm{~kg} \times \mathrm{kg}^{-1} \times$ day $^{-1}$ & $6.00 \times 10^{-8}[34]$ & $4.30 \times 10^{-7}[34]$ \\
\hline$N E C_{t, \text { subs }}$ at an organic carbon content of $2 \%$ & $\mathrm{~g} \times \mathrm{kg}^{-1}$ & $6.42 \times 10^{-5}[47]$ & $1.00 \times 10^{-11}[47]^{*}$ \\
\hline$N E C_{a, \text { sabs }}$ & $g \times 1^{-1}$ & $1.70 \times 10^{-5}[46]$ & $3.50 \times 10^{-5}[46]$ \\
\hline
\end{tabular}

- If a NEC value is unknown it is assumed to be $1.00 \times 10^{-11}$ (see discussion).

Table 6: The HTP of phenol and benzene; phenol and air are taken as refsubs resp. refcomp.

\begin{tabular}{lllllll}
\hline & \multicolumn{6}{l}{ phenol } \\
\cline { 2 - 7 } initial emission compartment & $K_{r} / N E I_{r}$ & $K_{o} / N E I_{o}$ & $H T P$ & $K_{r} / N E I_{r}$ & $K_{o} / N E I_{o}$ & $H T P$ \\
\hline air & $1.72 \times 10^{-5}$ & $8.43 \times 10^{-5}$ & 1 & $6.57 \times 10^{-3}$ & $2.11 \times 10^{-5}$ & 64.9 \\
water & $1.55 \times 10^{-9}$ & $1.13 \times 10^{-5}$ & 0.111 & $7.02 \times 10^{-4}$ & $2.32 \times 10^{-5}$ & 7.14 \\
soil & $6.81 \times 10^{-9}$ & $4.32 \times 10^{-3}$ & 42.6 & $6.43 \times 10^{-3}$ & $4.01 \times 10^{-3}$ & 103 \\
\hline
\end{tabular}

The toxicity potentials of benzene are dominated by its high volatility, which is seen in relatively high values for the $K / N E I$ ratio for the respiratory route. Furthermore, it is shown that the AETP and the TETP are the highest for emissions to resp. air and water, which is explicable as aquatic ecosystems will be most affected by direct emissions to water and terrestrial ecosystems will be most affected by direct emissions to soil. Notice that the high values for the TETP of benzene are caused by the $10^{-11}$, due to the absence of a terrestrial NEC for benzene. 
Table 7: The TETP and AETP of phenol and benzene; phenol and air are taken as refsubs resp. refcomp.

\begin{tabular}{lcccc}
\hline type of potential \& initial emission compartartment & \multicolumn{3}{c}{ phenol } & \multicolumn{2}{c}{ benzene } \\
\hline terrestrial ecotoxicity & $K / N E C$ & TETP & K/NEC & TETP \\
\hline air & $9.2 \times 10^{-11}$ & 1 & $1.75 \times 10^{-3}$ & $1.91 \times 10^{7}$ \\
water & $8.28 \times 10^{-15}$ & $9.01 \times 10^{-5}$ & $1.88 \times 10^{-4}$ & $2.04 \times 10^{6}$ \\
soil & $4.73 \times 10^{-9}$ & 51.5 & $3.43 \times 10^{-1}$ & $3.73 \times 10^{9}$ \\
\hline aquatic ecotoxicity & $K / N E C$ & $A E T P$ & $K / N E C$ & $A E T P$ \\
\hline air & $1.67 \times 10^{-8}$ & 1 & $3.85 \times 10^{-8}$ & 2.30 \\
water & $6.78 \times 10^{-7}$ & 40.5 & $1.33 \times 10^{-6}$ & 79.6 \\
soil & $1.98 \times 10^{-9}$ & 0.118 & $5.28 \times 10^{-8}$ & 3.15 \\
\hline
\end{tabular}

\section{DISCUSSION}

The method for the classification of toxic substances discussed above needs further elaboration. Aspects to be considered include the choice of the reference substance, the adaptation of Mackay models for different groups of substances, the data needed and refinement of the human exposure routes in the model.

In the selection of the reference substance technical criteria are relevant. Because the modelling constant of the reference substance $\boldsymbol{K}_{\text {refsubs,refecomp }}$ is in the denominator of the definition of the classification factor, the most important technical criterium is that the modelling constant of the reference substance be non-zero. This means that in an equilibrium situation, an emission of the reference substance to air results in a concentration both in soil and in water in order to be able to calculate the exposure part of the classification factors for ecotoxicity. Another important technical criterium is that for the reference substance an ADi- or TDI-value is available. Phenol seems to meet these criteria as it is a substance that is dispersed through all environmental compartments and a TDI-value is available; a TAC- or AQG is lacking and a $N E C$, has to be derived from the TDI according to equation (22). Of course, it is possible to choose another reference substance in the model proposed. If a reference substance of which many toxicological data are known is chosen, it may be interesting to investigate the possibility to use data from comparable ecotoxicological experiments instead of applying the EPA extrapolation factors. Moreover, the use of extrapolation factors is disputed; for example, it does not consider bioaccumulation through foodchains [48].

The Mackay model as discussed above uses fugacity as an equilibrium criterion to determine the environmental fate of emissions of chemicals. This approach is suitable for chemicals which can establish measurable concentrations in the vapor phase. It is not applicable to some metals, organometals, ionic compounds and some organics such as polymers that lack a vapor pressure [49]. Mackay \& Diamond [49] proposed to use a so-called "equivalent aqeous" concentration instead of the fugacity as an equilibrium criterion for substances that lack a vapor pressure. In this case, however, empirical data about the magnitude of the partitioning coefficients between various environmental media of a particular substance are necessary. As these are often lacking, this problem clearly needs further attention.

To calculate the different modelling constants based on a Mackay level III model, quite a number of physical data and toxicity data per substance are required, see table 5. As mentioned above, the type of physical data required may be different 
for inorganic substances. Some of these data are documented in comprehensive handbooks [45, 50], but it will be difficult to gather all these data for the most relevant toxic substances, especially data on degradation kinetics. As the practical applicability of the HTP-, TETP- and AETP-approach depends on the availability of these data, it should be emphasized that these data should preferably be gathered in a more structural way and stored in a database, and be regularly updated to the latest state of knowledge. Despite the fact that some data may be missing for the time being, we still think that this approach is a substantial improvement of former methods for the classification of toxic chemicals, because it includes exposure routes and relevant toxicity data. To deal with this current lack of data it is suggested that if for a chemical degradation data or toxicity data are missing, they are assumed to be zero until proven untrue. For computational reasons, a lacking toxicity entry should be approached by a very small number instead of 0 , e.g. $10^{-11}$.

The modelling of the exposure routes to human beings might need further improvement. Basically, an emission of a substance can lead to human exposure in three ways:

- direct: via respiration and consumption of (drinking) water;

- indirect: via the consumption of fish, meat, dairy products and crops;

- secondary indirect: by consumption of the same products produced with sludge and manure, which are polluted "coproducts" of drinking water purification resp. meat production.

In the model described, the direct and indirect routes are included, although incompletely. For example, exposure by skin contact (soil, air, water or the product itself) is not included. Two other examples are the exposure to a substance by drinking water and respiration. In equation (14) the concentration of the substance in drinking water is assumed to be equal to the concentration in unpurified surface water, thus not considering drinking water purification systems [cf. 24]. The exposure to a substance by respiration (equation (12)) includes a similar "overestimation" as a part of the world population respires mainly relatively "airconditioner clean" indoor air. These obvious "over-estimation" of human exposure by drinking water and respiration can be compensated by including averaged purification data per substance, if known. If such data are included, it is important to also include the secondary indirect routes (which are not yet considered at all). Secondary exposure routes exist if the exposure routes pass economic processes, such as agriculture and purification of drinking water. Modelling of these processes raises some problems. Economic processes have a number of inputs, such as grass and cattle feed resp. unpurified surface water, and a number of outputs, such as meat, dairy products and manure resp. drinking water and sludge. Exclusion of this secondary indirect exposure route is probably justified if the degradation time of a substance in sludge and manure that is used again as a fertilizer in agriculture, is relatively low compared to the time it takes to pass the secondary route. However, for persistent substances such as heavy metals and some pesticides, exclusion seems not justified. The extent of this potential "underestimation" can be calculated by, for example, estimating the amount of the substance considered in the manure. This amount could then be defined as an emission again and the secondary indirect exposure could be calculated with the same model. It is recommended here, that the influence of this secondary indirect exposure be further investigated. Refinement of the direct and indirect routes together with the inclusion of secondary indirect routes are subjects for further research.

Finally, it is suggested to create an international scientific panel, which could discuss proposals for classification factors, such as these here, and coordinate scientific efforts made in the different environmental fields. Comparable with the scientific assessment panel for ozone depletion under the auspices of the Wrrld Meteorological Organization (WMO) and the intergovernmental panel on climate change (IPCC) for global warming under the auspices of wMo and United Nations Environment Programme (UNEP), panels might be established for human toxicity and ecotoxicity. With respect to the latter, initiatives are currently being taken. 


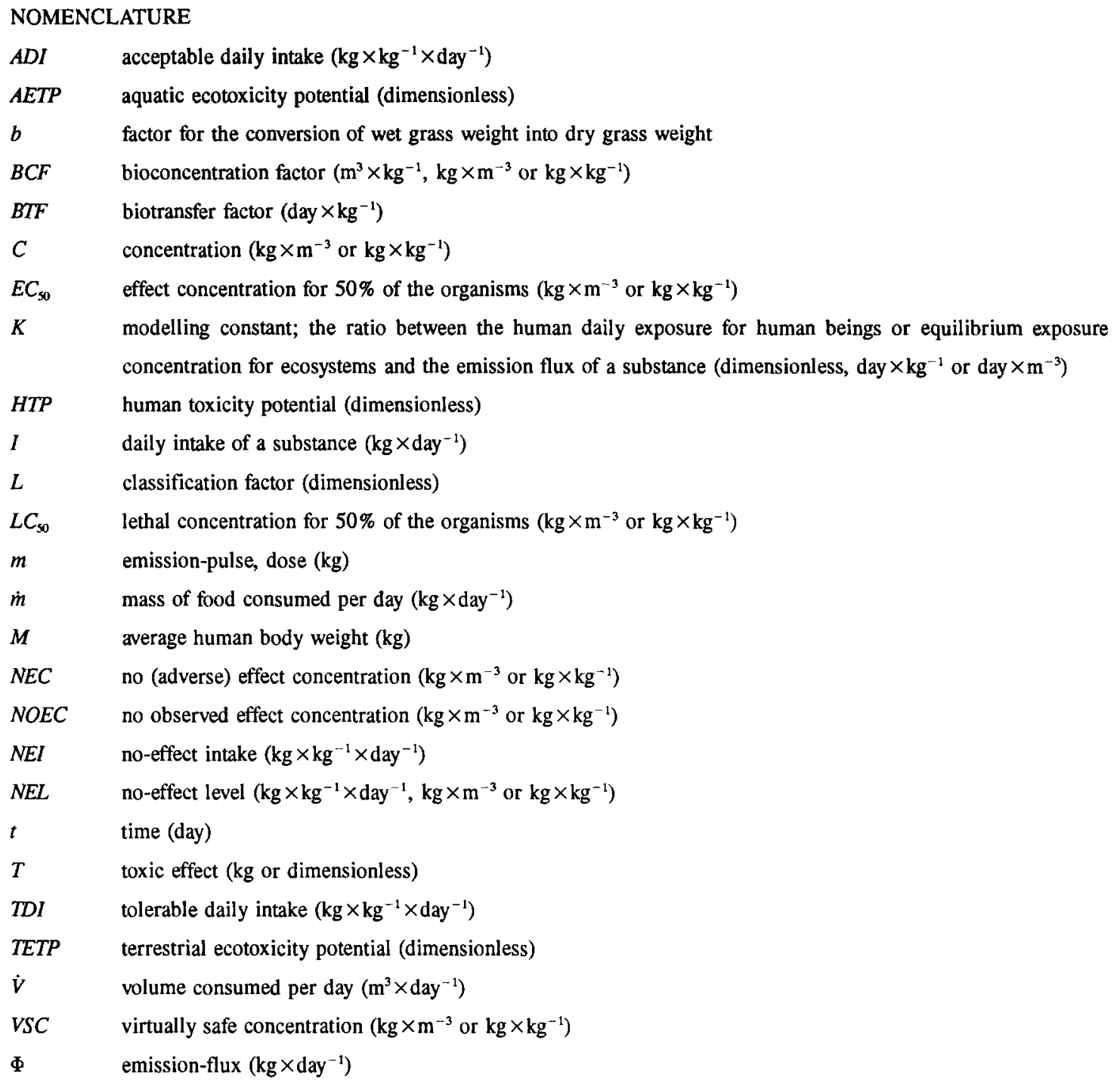

\section{ACKNOWLEDGEMENTS}

We especially thank Anneke Wegener Sleeswijk, René Kleijn (both Leiden University), Lucie Vollebregt (University of Amsterdam), Theo Vermeire, the late Christian Toet (both RIVM) and Peter van der Zandt (VROM) for their contributions to this paper.

\section{REFERENCES}

1. Smet, B. de (editor), 1990: Life-cycle analysis for packaging environmental assessment. Proceedings of the specialized workshop, 24-25 september 1990 in Leuven. Procter \& Gamble Technical Center, Strombeek-Bever.

2. Fava, J.A., R. Denison, B. Jones, M.A. Curran, B. Vigon, S. Selke, J. Barnum (eds.), 1991: A technical framework for life-cycle assessments. SETAC, Washington.

3. Udo de Haes, H.A., 1992: A general framework for environmental life-cycle assessment of products. In: Proceedings of SETAC-Europe workshop on environmental life cycle analysis of products. Brussels. 
4. Guinée, J.B., H.A. Udo de Haes and G. Huppes, 1992: Quantitative Life Cycle Assessment of Products: Goal Definition and Inventory. Accepted for publication in the Journal of Cleaner Production.

5. Guinée, J.B., R. Heijungs, H.A. Udo de Haes and G. Huppes, 1992: Quantitative Life Cycle Assessment of Products: Classification, Valuation and Improvement Analysis. Accepted for publication in the Journal of Cleaner Production.

6. Fava, J.A., F. Consoli, R. Denison, K. Dickson, T. Mohin and B. Vigon, 1992: Workshop report conceptual framework for life-cycle impact analysis. Draft. Report of the workshop on Impact Analysis, February 1-7, 1992. Sandestin (Florida).

7. Heijungs, R., J.B. Guinee, G. Huppes, R.M. Lankreijer, A.M.M. Ansems, P.G.Eggels, R. van Duin \& H.P. de Goede, 1991: Manual for the environmental life cycle assessment of products. CML, Leiden.

8. Guinée, J.B., 1992: Headings for Classification. In: Life-Cycle Assessment; Proceedings of SETAC-Europe workshop on Environmental Life-Cycle Assessment of Products, December 2-3 1991 in Leiden. SETAC-Europe, Brussels.

9. Baumann, H., T. Ekvall, T. Rydberg, G. Svensson \& A.-M. Tillman, 1991: Operationalization of the classification. In: Proceedings of SETAC-Europe workshop on environmental life cycle analysis of products. Brussels.

10. Finnveden, G., Y. Andersson-Sköld, M.-O. Samuelsson, L. Zetterberg and L.-G. Lindfors, 1992: Classification (Impact Analysis) in connection with Life Cycle Assessments. A Preliminary Study. In: Product life cycle assessment. Principles and methodology. Nord, Copenhagen/Stockholm.

11. Houghton, J.T., G.J. Jenkins \& J.J. Ephraums (eds.), 1991: Climate change. The IPCC scientific assessment. Cambridge University Press, Cambridge.

12. WMO, 1989: Scientific assessment of stratospheric ozone. Volume I; report no. 20. WMO/UNEP, Geneva.

13. UNECE, 1990: Draft technical annex on classification of volatile organic compounds based on their photochemical ozone creation potential (POCP). United Nations Economic Commision for Europe (Economic and Social Council), Geneva.

14. Heijungs, R., J.B. Guinée, G. Huppes, R.M. Lankreijer, H.A. Udo de Haes, A. Wegener Sleeswijk, A.A.M. Ansems, P.G. Eggels, R. van Duin and H.P. de Goede, 1992 (final report, forthcoming): Environmental life cycle assessment of products. Guide - October 1992. Centre of Environmental Science, Leiden University.

15. Basler \& Hofman Ingenieure und Planer, 1974: Studie Umwelt und Volkswirtschaft, Vergleich der Umweltbelastung von Behaltern aus PVC, Glas, Blech und Karton. Eidgenössisches Amt für Umweltschutz, Bern.

16. Bus, 1984: Ökobilanzen won Packstoffen. Schrifienreihe Umweltschutz no. 24. Bundesamt für Umweltschutz.

17. Mekel, O.C.L., G. Huppes, R. Huele, \& J.B. Guinée, 1990: Environmental effects of different package systems for fresh milk. CML report 70, Leiden.

18. Klöpffer, W., 1989: Environmental hazard assessment of anthropogenic chemicals. In: Zirm, K.L. \& J. Mayer, 1989a: The management of hazardous substances in the environment. Proceedings of first international ISEP Congress on 20-22 February 1989, Vienna, Austria. Elsevier, London/New York.

19. Dieter, H.H., U. Kaiser \& H. Kerndorff, 1990: Kontaminanten aus Altlasten. Vorschlag zur standandisierten toxikologischen Bewertung. Z. Umweltchem. Ökotox. 2 (1).

20. Meent, D. van de, 1989: Beoordelingssysteem nieuwe stoffen; SIMPLERISK, een model voor het schatten van locale concentraties in water en bodem. RIVM report no. 718706001. Bilthoven.

21. Mackay, D. \& A. Paterson, 1981: Calculating fugacity. Environ. Sc. Technol. 15, pp. 1006-1014.

22. Mackay, D. \& A. Paterson, 1982: Fugacity revisited. Environ. Sc. Technol. 16 (12), pp. 654-660.

23. Mackay, D., 1991: Multimedia Environmental Models, the fugacity approach. Lewis Publ. Inc. Chelsea.

24. Toet, C., A.C.M. de Nijs, T.G. Vermeire, P. van der Poel \& J. Tuinstra, 1991: Risk assessment of new chemical substances; system realisation and validation II. RIVM report no. 679102004. Bilthoven. 
25. Toet, C. \& D. van de Meent, 1992: Priority setting system for existing chemicals. Paper presented at the meeting of the steering group of the project "Uniform System for the Evaluation of Substances (USES)". RIVM. Bilthoven.

26. Guinée, J.B. and R. Heijungs, 1992: Classification factors for toxic substances within the framework of life cycle assessment of products. CML paper no. 11. Centre of Environmental Science Leiden University, Leiden.

27. Nijs, A.C.M. and T.G. Vermeire, 1990: Soil-plant and plant-mammal transfer factors. RIVM report no. 670203001. Bilthoven.

28. Mackay, D., 1982: Correlation of bioconcentration factors. Envir. Sc. Technol. 16 (5), pp. 274-278.

29. Briggs, C.G., R.H. Bromilow and A.A. Evans, 1982: Relationships between lipophilicity and root uptake and translocation of non-ionised chemicals by Barley. Pestic. Sci. 13, pp. 495-504.

30. Briggs, C.G., R.H. Bromilow, A.A. Evans and M. Williams, 1983: Relationship between lipophilicity and the distribution of non-ionised chemicals in barley shoots following uptake by the roots. Pestic. Sci. 14, pp. 492-500.

31. Travis, C.C and A.D. Arms, 1988: Bioconcentration of organics in beef, milk and vegetation. Environ. Sci. Technol. 22, pp.271-274.

32. Meent, D. van de, 1991a: Beoordelingssysteem Nieuwe Stoffen, risicoschatting sedimentorganismen; een verkennende studie. RIVM report no. 679102001 . Bilthoven.

33. Vermeire, T.G., A.A.J. van Iersel, F.A.A.M. de Leeuw, W.J.G.M. Peijnenburg, P. van der Poel, R.D.F.M. Taalman \& C. Toet, 1992: Initial assessment of the hazards and risks of new chemicals to man and the environment. RIVM report no. 679102006. Bilthoven.

34. Vermeire, T.G., M.E. van Apeldoorn, J.C. de Fouw \& P.J.C.M. Janssen, 1991: borstel wor de humaantoxicologische onderbouwing van C-(toetsings)waarden. RIVM report no. 725201005. Bilthoven.

35. who, 1987: Air quality guidelines for Europe. who Regional Publications, european Series No. 23. Copenhagen.

36. Straalen, N.M. van, P. Leeuwangh \& P.B.M. Stortelder, 1991: Voortschrijdende grenzen. Bodem (2), 1991, pp. 5156.

37. EPA, 1984: Estimating concern levels for concentrations of chemical substances in the environment. EPA, Environmental Effects Branch Health and Environmental Review Division. Washington.

38. Slooff, W., 1992: Ecotoxicological effect assessment; Deriving Maximum Tolerable Concentrations (MTC) from singlespecies toxicity data. RIVM report no. 719102018. Bilthoven.

39. Straalen, N.M. van \& C.A.J. Denneman, 1989: Ecotoxicological evaluation of soil quality criteria. Ecotox. Environ. Saf. 18, pp. 241-251.

40. Kooijman, S.A.L.M., 1987: A safety factor for $L C_{s 0}$ values allowing for differences in sensitivity among species. Water res. 21, 269-276.

41. Aldenberg, T. \& W. Slob, 1991: Confidence limits for hazardous concentrations based on logistically distributed NOEC toxicity data. RIVM report no. 719102002 . Bilthoven.

42. Wagner, C. \& H. Lokke, 1991: Estimation of ecotoxicological protection levels from NOEC toxicity data. Wat. Res. vol. 25 no. 10, pp. 1237-1242.

43. Mackay, D., S. Paterson and B. Cheung, 1985: Evaluating the environmental fate of chemicals the fugacity-level III approach as applied to 2,3,7,8-TCDD. Chemosphere, 14, no. 6/7, pp. 859-863.

44. Mackay, D. and S. Paterson, 1991: Evaluating the multimedia fate of organic chemicals; a level III fugacity model. Environ. Sc Technol. 25 (3), pp. 427-436.

45. Howard, P.H., 1989: Handbook of environmental fate and exposure data for organic chemicals. Volume I (Large Production and Priority Pollutants) and II (Solvents). Lewis Publishers, Chelsea (Michigan). 
46. Stortelder, P.B.M., M.A. van der Gaag en L.A. van der Kooij, 1989: Kansen voor waterorganismen; Normstelling, 2, Basisgegevens. DBW/RIZA nota nr. 89.016b. Lelystad.

47. Denneman, C.A.J. en C.A.M. van Gestel, 1990: Bodenverontreiniging en bodemecosystemen; voorstel voor c(toetsings)waarden op basis van ecotoxicologische risico's. RIVM rapport nr. 725201001. Bilthoven.

48. Tamis, W.L.M. en F.M.W. de Jong, 1992: Validatie in een milieukundig perspectief. Paper presented at the RIVMworkshop "Validatie van toxiciteitsgegevens en risicogrenzen", june 10, 1992. Centre of Environmental Science, Leiden University. Leiden.

49. Mackay, D. and M. Diamond, 1989: Application of the QWASI (Quantitative Water Air Sediment Interaction) fugacity model to the dynamics of organic and inorganic chemicals in lakes. Chemosphere, 18, pp. 1343-1365.

50. Verschueren, K., 1983: Handbook of environmental data on organic chemicals. Van Nostrand Reinhold Company Inc., New York. 